\title{
Revisitando Questões sobre Lei, Transgressão e Família em suas Interações com a Psicologia, a Psicanálise, o Direito e a Interdisciplinaridade Possível
}

Júlia Sursis Nobre Ferro Bucher-Maluschke Universidade de Brasília

Universidade de Fortaleza

\begin{abstract}
RESUMO - Neste ensaio são apresentados os principais desenvolvimentos ocorridos após a publicação do artigo "Leis, transgressões, famílias e instituições: elementos para uma reflexão sistêmica”, de minha autoria, publicado em 1983, no que concerne às leis e as novas configurações familiares. São apresentados resultados da percepção de segmentos da população acerca do significado da lei à luz dos resultados da pesquisa realizada há 14 anos. Discorremos sobre as transformações das interações da Psicologia e da Psicanálise com o Direito, assim como as contribuições da Teoria Sistêmica. Ilustramos a mediação de conflitos, uma nova área multidisciplinar, como a mais recente contribuição prática integrando Psicologia, Direito e outras áreas do conhecimento.
\end{abstract}

Palavras-chave: psicologia e direito; família e legislação; mediação de conflitos; psicanálise e direito.

\section{Revisiting Questions Regarding Law, Transgression and Family in their Interactions with Psychology, Psychoanalysis, and Law and the Plausible Interdisciplinary Relationship}

\begin{abstract}
This essay presents the principal developments concerning the laws and new family configurations since the 1983 publication of my article "Laws, transgressions, families, and institutions: elements for a systemic reflection." Results are presented of the perceptions of population segments regarding the significance of law in light of the results of research conducted 14 years ago. We discuss the transformation in the interactions of Psychology, Psychoanalysis and Law, as well as the contributions of Systemic Theory. We illustrate conflict medication, a new multidisciplinary area, as the most recent, practical contribution of integrating Psychology, Law and other areas of knowledge.
\end{abstract}

Key words: psychology and law; family and legislation; conflict mediation; psychoanalysis and law.

Há 14 anos, apresentamos o artigo intitulado "Lei, transgressões, famílias e instituições: elementos para uma reflexão sistêmica", publicado na Psicologia: Teoria e Pesquisa. As reflexões procedidas originaram-se a partir da experiência obtida nos trabalhos desenvolvidos nas esferas jurídicas no Distrito Federal. Neste artigo, trazemos algumas transformações ocorridas desde então nas interações da Psicologia com o Direito, área à qual o tema anterior estava subordinado.

Em 1978, inauguramos na Defensoria Pública, integrante, na época, do Ministério Público do Distrito Federal e dos Territórios, localizado em Brasília, um estágio supervisionado em que congregávamos estudantes de Psicologia com a participação de uma assistente social (Bucher, 1979a, 1979b, 1981b).

Iniciava-se naquela época, talvez pioneiramente, uma articulação entre o trabalho de Psicologia e o Direito voltado para as questões de família e de casais, tendo culminado com a realização, na Universidade de Brasília, do Seminário $O$ casal e a Lei com a participação de professores do Direito, da Psicologia e de psicanalistas e a conseqüente publicação dos trabalhos apresentados nos Arquivos do Ministério da Justiça (Bucher, 1981a).
Outra frente de trabalho foi estruturada no Juizado de Menores, na década de 1980, com a introdução de cursos de formação para os profissionais daquele órgão do Distrito Federal tendo como tema central a Família, com um de seus membros menores de idade tendo envolvimento com a lei, numa perspectiva sistêmica. Estas experiências, pioneiras no Distrito Federal, foram marcos fundamentais para a formação da primeira geração de profissionais aptos ao trabalho nesta perspectiva interdisciplinar.

Nesta ocasião fundamos o Centro Brasileiro de Estudos da Família cujo objetivo foi formar terapeutas de família e casal para atender a demanda crescente na população. Paralelamente a esse trabalho, supervisionamos estágios realizados tanto nas dependências da Defensoria Pública quanto na antiga UEEP (Unidade Especial de Ensino e Pesquisa, hoje Centro de Atendimento e Estudos Psicológicos - CAEP) vinculada ao Departamento de Psicologia Clínica, onde nas décadas de 1970 e 1980 inúmeros casos de conflitos conjugais e familiares com envolvimento com a lei foram atendidos por estagiários sob nossa supervisão.

Nas duas últimas décadas, o trabalho do psicólogo na área jurídica tem se desenvolvido nos mais variados âmbitos dos 
setores da Justiça, tanto no campo das intervenções quanto no terreno dos estudos e das pesquisas. Na seara da família, quando em interação com os procedimentos legais em função de alguma demanda, os psicólogos têm atuado em varas de família (adoção, investigação de paternidade, guarda dos filhos, divórcio, casamentos, mediação de conflitos etc), criminais e da infância e juventude. $\mathrm{O}$ aumento de uma literatura atinente a estas realidades, sobretudo a partir dos anos 2000, é fruto da interação dessas duas importantes frentes de atuação profissional conforme nos atestam os trabalhos de Caíres (2003); Cruz; Maciel e Ramirez (2005); Rigonatti (2003); Silva (2003) e Souza (1999).

Neste texto, procuraremos apresentar os principais desenvolvimentos ocorridos nos últimos 14 anos, decorridos após as primeiras idéias apresentadas no artigo original. Inicialmente, abordaremos as mudanças na família oriundas das transformações das leis nesse período. Em seguida, a partir dos resultados obtidos em pesquisas realizadas nos últimos anos, traremos algumas reflexões sobre a evolução da percepção, do significado da lei para os membros das famílias, comparando-os com os resultados colhidos em nosso estudo anterior. Finalmente, mostraremos as transformações das interações do Direito a partir das contribuições da Psicologia e da Psicanálise, e em que medida a Teoria Sistêmica contribuiu para essas transformações com incidência na prática profissional, em especial em relação ao surgimento de mais uma área da prática interdisciplinar: a mediação de conflitos.

\section{Mudanças na Configuração Familiar e a Evolução no Campo das Leis}

A família passa por profundas transformações. Em estudos anteriores, destacamos os cenários em que essas mudanças estão ocorrendo, ocasionadas por transformações sociais, econômicas, culturais e tecnológicas (Bucher, 1999; BucherMaluschke, 2003; Bucher-Maluschke \& Costa, 2003). Em conseqüência, o pátrio poder regido nas famílias patriarcais está perdendo espaço e o casamento passa a ser cada vez mais regido pela affectio maritalis. Essa nova dimensão da união conjugal não foi acompanhada imediatamente pela legislação vigente, o que levou ao crescimento de famílias ilegítimas paralelas às famílias legítimas. A partir dessa realidade, vão aumentando as pressões para a modernização das leis vigentes e mudanças na legislação foram surgindo (Andreotti-Neto,1991; Angher, 2003).

Em 1962, surge a Lei $n^{\circ} .4 .121$, emancipando a mulher casada que até então era considerada como relativamente incapaz. Em 1977, com a Lei nº 6.515 , o divórcio é regulamentado, introduzido pela Emenda Constitucional $\mathrm{N}^{\mathrm{o}}$ 9/77. Estes são os primórdios das transformações legais que seguirão nas contribuições trazidas na nova Constituição Federal de 1988.

Não resta dúvida de que essas transformações legais chegaram muito tempo depois das mudanças reais ocorridas na família em que se criaram inúmeros artifícios, tais como os rituais legitimando a realidade existente. Convém lembrar aqui os casamentos realizados no Uruguai, onde havia o divórcio, e quantos brasileiros voltavam festejando o seu casamento legitimado naquele país. Para a celebração religiosa do casamento "ilegal", muitos recorriam à denominada Igreja Católica Brasileira, onde eram realizados os rituais de celebração que não eram possíveis na Igreja Católica Romana.

No âmbito do Direito da Família, nova estrutura foi definida conforme nos atestam os conteúdos dos artigos 226 a 230 da Constituição Federal. Homem e mulher passam a ser equiparados ao obterem direitos e deveres iguais. Os filhos de qualquer origem passam a ser legitimados e as discriminações em relação a eles são terminantemente proibidas. $\mathrm{O}$ conceito de família se amplia, com o reconhecimento das uniões estáveis e inclusão das famílias monoparentais como grupo familiar. Tais direitos obtidos na Carta Magna passam a ser incorporados no novo Código Civil de 2002.

A legitimação da união dita "livre" ocorreu a partir da regulamentação do direito dos companheiros a alimentos e a sucessão, com a Lei n ${ }^{\circ}$. 8.071, de 29 de dezembro de 1994. Enquanto isso, a Lei no ${ }^{\circ}$ 9.278, de 10 de maio de 1996, legitimou a segunda forma de constituição da entidade familiar, ao considerar a união estável como legalmente constituída.

$\mathrm{Na}$ área da criança e do adolescente, uma contribuição importante do ponto de vista legislativo foi a criação do Estatuto da Criança e do Adolescente, sancionado pela Lei $\mathrm{n}^{\circ}$. 8.069/90, a partir da qual é estabelecido maior número de direitos dos pais em relação aos filhos do que poderes, o que caracterizou mudança na concepção tradicional de pátrio poder.

Outra contribuição importante é a amparada pela Lei $\mathrm{n}^{\circ}$. 8.560, de 29 de dezembro de 1992, ao incumbir o Ministério Público de ministrar a ação de investigação de paternidade, com o fim de obter o reconhecimento da filiação paterna em caso de dúvida ou quando não há reconhecimento voluntário da paternidade por parte do pai.

A consangüinidade como prova da definição de filiação biológica não possuía um correlato na realidade jurídica, a não ser pela declaração voluntária do reconhecimento de sua paternidade pelo próprio pai, até o advento da tecnologia que permitiu, com exatidão, a determinação da paternidade biológica nos casos em que esse reconhecimento não foi realizado. Isto levou às mudanças no Direito de Família que passou a permitir a possibilidade da investigação da paternidade biológica, obrigando que o pai procriador passasse a assumir suas responsabilidades civis perante o filho.

Convém observar que no artigo 229 da Constituição Federal de 1988 o dever genérico imposto aos pais de assistir, criar e educar os filhos menores assegurou, por sua vez, o dever dos filhos de ajudar e amparar os pais na velhice, na carência e na enfermidade, o que, conforme Barros (2001) levam à substituição da expressão pátrio-poder, em certa medida, pela de pátrio-dever.

O artigo 227 da Constituição Federal de 1988, parágrafo VI, transformado nas Leis $\mathrm{n}^{\circ}$. 8.069/90 e $\mathrm{n}^{\circ}$. 8.560/92, não diferencia mais filhos legítimos e ilegítimos, que passam a ter os mesmos direitos e qualificações, sendo proibido qualquer tipo de discriminação.

Não devemos nos esquecer de que durante muitas décadas, o nascimento de uma criança fora do casamento legitimado, foi considerado pejorativamente como "filho da mãe" e, por este fato, muito discriminado por vários setores da sociedade, sendo inclusive chamado e considerado como "bastardo". 
Essas leis, ao entrarem em vigor, proporcionaram paulatinamente mudanças significativas no âmbito da vida das pessoas e de suas famílias. Muitos foram os casos atendidos em psicoterapia, com relatos apresentando intenso sofrimento psíquico, vivenciado em conseqüência das discriminações sofridas, que perduraram ao longo de suas vidas, não só por pessoas próximas, quanto por instituições, nas quais se destacaram as escolas. O não-reconhecimento por parte do pai foi um tema muito importante, a ser considerado na área da Psicologia Clínica.

Outra configuração familiar expressa na nova legislação foi o da família monoparental. De acordo com o parágrafo $4^{\circ}$ do artigo 226 da Constituição Federal, o cônjuge vivendo com os filhos torna-se uma família denominada monoparental, que pode ser materna ou paterna, diferenciada do biparental até então a única vigente nos parâmetros da legalidade. Esta legalização de famílias monoparentais surgiu por vários motivos: mãe solteira com filhos, mulher solteira adotando filhos e, pelo surgimento de técnicas de reprodução artificial humana, possibilitando in vitro à mulher solteira que optou por ter um filho sem que tenha relacionamento sexual com um parceiro estável.

Este aspecto vinculado à tecnologia, juntamente com gravidez de mãe solteira, ou de adoção, por uma mulher solteira ou por um homem solteiro e sem vínculos estáveis com outros, são as razões que levaram o legislador a preservar o direito, dessa parcela da população, de terem filhos e de formarem uma família.

O Brasil, muito antes dos avanços tecnológicos, se caracterizou por um crescimento de famílias monoparentais maternas, na medida em que a mulher assumia a responsabilidade pelos filhos, independentemente do marido ou dos pais dos seus filhos, conforme nos atesta o trabalho de Costa (2001).

Não podemos esquecer de que a família tem como pressuposto algumas leis que devem ser observadas: a interdição de impulsos básicos traduzidos pelo incesto e parricídio, já assinalados por Freud (1972) e Levi-Strauss (1982), temas esses atualmente abordados pela Psicanálise em sua aproximação com a área do Direito.

A temática aqui apresentada das transformações nas configurações familiares e das mudanças das leis é assunto que merece muitos estudos, em decorrência da sua complexidade e das repercussões do ponto de vista psicológico, que podem estar ocorrendo nas famílias e seus membros.

Abordaremos a seguir, o outro aspecto que foi objeto do nosso estudo anterior, procurando identificar o que mudou a partir do estudo revisitado.

\section{A percepção da lei mediante as pesquisas}

Em 1983, levamos a público os resultados de uma pesquisa realizada sobre o significado psicossocial da lei para a família e seus membros. Naquela ocasião, os resultados apontaram para uma percepção da lei como um instrumento para a proteção pessoal contra o que é realmente ameaçador, contra o que não é possível controlar. Outra interpretação dada foi a de servir para a proteção dos ricos e não para a proteção de todos, favorecendo os ricos ou só existindo em benefício próprio.
A lei, portanto, era percebida como exterior à realidade vivida pelos pobres, levando-os à necessidade do uso da força física como fator que a determinaria como sendo a "lei dos mais fortes" e a "lei dos mais fracos fisicamente", passando a ser a "lei do engodo". "O mais fraco tem que camuflar, enganar, burlar as leis, as regras, pois, elas são feitas contra eles". Concluímos, a partir daquele estudo, que havia uma ruptura entre a lei maior, em que estava implícito o respeito ao outro, e essa "lei paralela ou uma nova regra", indicando confusão nos códigos de valores.

Novas pesquisas foram realizadas junto à população, visando à identificação das representações sociais que ela têm da lei, da justiça, da injustiça, do juiz e temas correlatos, o que nos permite ver que transformações ocorreram neste período.

A pesquisa desenvolvida por Jovchelovitch (2000), teve como tema as representações sociais e esfera pública e a construção simbólica dos espaços públicos no Brasil. Neste livro, o que nos chama a atenção é o fato de que o principal aspecto que emerge nas representações dos brasileiros sobre a vida pública é a corrupção. Para a autora, a corrupção apresenta-se como uma realidade imutável, em conseqüência da relação entre "poderosos" e "sem poder". Os poderosos representam a onipotência e os sem poder a impotência, levando a um fatalismo. É interessante observar que isto se mantém nos resultados desta pesquisa, comparando com os que socializamos no nosso artigo há 14 anos: o hiato entre um "código constitucional explícito e escrito e um código de práticas implícito".

Em 2000, Menin realizou uma pesquisa sobre as representações de justiça com adolescentes infratores na faixa etária de 12 a 17 anos, que haviam sido notificados a comparecer na Promotoria Pública, por terem se envolvido em infrações, como: furtos, brigas, usos de dinheiro falso e dirigir carro sem habilitação.

Entre os instrumentos utilizados, destacamos uma entrevista a partir de um roteiro estruturado, visando a identificar as associações livres ligadas às palavras justiça, lei, injustiça, juiz. Foi também expressa uma pequena história adaptada na qual a pesquisadora abordou a questão da lei e seu cumprimento, e utilizou uma escala para cada diferente tipo de infração, na qual os entrevistados deveriam classificá-la numa gradação, apontando para o grau de gravidade do ato. Os resultados indicaram que a palavra justiça foi associada ao crime, à punição (pena, acusação, cadeia); à palavra lei foram associadas obrigação, obediência, dever, fórum, violência, polícia, delegado, o certo e o errado; a palavra injustiça foi ligada a transgressão, pessoas de autoridade, punição imerecida, falsa acusação e o que é oposto a justiça. $\mathrm{O}$ vocábulo juiz vinculou-se à idéia de autoridade, o que manda, aquele que julga, ou o que absolve, aquele que representa a lei. Chamou a atenção da pesquisadora o fato de que foram poucas as associações obtidas para as quatro palavras.

Em relação à lei, a pesquisadora estruturou algumas perguntas, dentre as quais destacamos: $\mathrm{O}$ que aconteceria se não houvesse leis? E as respostas, em sua maioria, foram relacionadas ao caos, traduzido como todos iriam matar, roubar, apresentando um quadro de violência, ou, ainda, respostas indicando desrespeitos e arbitrariedades, levando à idéia de impunidade. 
A pergunta: "O que é a lei?" foi definida como uma ordem que temos de obedecer incondicionalmente. Algo a se obedecer para não ser punido, ordem provinda de uma autoridade e que permite saber como se deve agir. Por que as pessoas devem obedecer às leis? Para evitar o caos, para proteger as pessoas contra esse caos, para obedecer à lei, para evitar a punição e deve ser obedecida porque são leis. Por que você obedece às leis? A maior parte das respostas foi por ser uma obrigação, em seguida, para evitar punições, outras respostas, para a obtenção de uma auto-imagem positiva e para ser respeitado na sociedade.

As infrações mais graves, consideradas por todos ou quase todos os participantes foi: bater na mãe ou matar para roubar. As leis mais importantes para os adolescentes foram: a exigência de respeito mútuo, solidariedade e amizade, e a menos importante foi a punição dos infratores. Na questão sobre o que denunciaria como uma injustiça, o maior número de adesões foi: rico subornar ou haver corrupção dos poderosos; más ações, roubo, ameaças, tráfico, bandidos.

Dois anos depois, outra pesquisa é publicada por Shimizu e Menin (2004), tendo uma amostra de 621 jovens brasileiros e 200 jovens argentinos, na faixa etária de 13 a 17 anos, todos freqüentando a escola. Foram pesquisadas, junto a essas populações, as representações sociais de lei, de justiça e de injustiça, a partir da utilização da técnica da evocação livre de palavras como instrumento metodológico. Comentaremos os resultados dos jovens brasileiros.

No que diz respeito à lei, os resultados obtidos da associação de idéias a esta palavra foram: importante, ordem, obrigação, cumprir e dever. Para os brasileiros, a lei é carregada de um caráter impositivo, o que foi comprovado, segundo os autores dessa pesquisa, pela estreita relação apresentada entre as palavras ordem, obrigação, cumprir e dever. Nesta população estudada, "é um dever de todos que a lei seja cumprida, e, assim, a ordem se restabeleça". No que diz respeito, à palavra justiça, para os brasileiros, ela é, sobretudo, um direito que deve ser garantido pela lei. Ela deve fazer o que é certo e, portanto, é necessária. Quanto à injustiça, há forte consenso de que ela está vinculada à desigualdade, à corrupção e ao preconceito, assim como ao desrespeito, ao erro e à tristeza. Observou-se uma desconfiança dos brasileiros em relação à lei "vendo-a com olhar crítico os brasileiros expressam o resultado negativo da lei, quando não cumprida adequadamente, há injustiça" (p. 245).

No que diz respeito à palavra-estímulo injustiça, verificamos que as representações elaboradas pelos brasileiros referem-se ao sentido social da palavra - o que, talvez, esteja mais aparente em nossa sociedade. Representando-as com base no contexto da realidade social, os jovens descrevem a injustiça na forma da desigualdade, corrupção e preconceito e revelam as suas conseqüências: o crime e a pobreza; fazem um julgamento de valor em relação a essa realidade, ao assinalarem que é errada e que é um desrespeito. Demonstram sentirem-se amarrados em relação a esse contexto, ao expressarem que essa é uma "realidade triste".

Nos resultados dessas pesquisas, embora sejam mais abrangentes em termos da população estudada, ainda constatamos uma similitude com os resultados da investigação anterior. Embora os crimes ocorram nos mais variados estratos sociais, tem-se constatado que a impunidade é percebida e identificada por grande parcela da população. A corrupção também foi um tema que surgiu com bastante força nas representações sociais dos pesquisados, o que se diferenciou muito neste aspecto de nossa busca anterior.

As diferentes formas de se representar a lei e a ela se relacionar são determinadas pelo posicionamento socioeconômico dos sujeitos e pela maneira como suas necessidades são atendidas no contexto social. Eles continuam demonstrando também menor esclarecimento em relação às leis e, conseqüentemente, maior distanciamento e uma atitude mais submissa, passiva e fatalista em relação a elas.

Comparando esses dados com as observações no artigo de 1983, verifica-se que poucas foram as mudanças ocorridas. Apesar de a informação ter maior circulação, ainda há uma percepção truncada das leis vigentes. É importante que novas e amplas pesquisas sejam realizadas, levando em consideração as diferentes classes sociais, a escolaridade e o contexto familiar e social em que se encontram os participantes de tais estudos.

Consideramos, também, a necessidade de se introduzir noções acerca das leis na formação dos estudantes desde o $1^{\circ}$ grau, explicitando para que elas servem e por que devem ser cumpridas. Essa dimensão deve ser incorporada no processo educativo de todos, pois, desta forma, está se desenvolvendo neles a cidadania.

Um problema mais complexo apontado pelas pesquisas diz respeito ao sistema de crenças que integram a vida de uma parcela da população, identificando o significado social da lei e as formas de vivenciá-las, a partir da compreensão que circula no contexto imediato dessas pessoas. Neste âmbito, concluímos que é importante analisar criticamente esses sistemas de crenças, integrando em sua formação outros conceitos menos abordados, tais como os de solidariedade e compaixão.

O tema seguinte, revisitado e para aqui trazido, indica algumas das transformações a partir do primeiro artigo, considerando em especial a teoria sistêmica.

\section{O enfoque sistêmico na perspectiva do Direito e nas instituições jurídicas}

É da Sociologia que surge a grande contribuição teórica para o Direito na perspectiva sistêmica a partir dos trabalhos de Luhmann (1983, 1988, 1995) e Teubner (1988, 1989, 1996). Eles consideram fundamental o problema da relação entre o Direito e a sociedade (Luhmann, 1983; Teubner, 1996).

Luhmann (1995) exprime uma concepção sistêmica, procurando explicar os padrões recursivos das interações dos agentes sociais que formam sistemas de comunicação. Ele aponta também para os conceitos de sistemas abertos e sistemas fechados, sendo que os sistemas sociais são abertos. Para ele os sistemas são orientados pelos seus ambientes. A estrutura geral da teoria da sociedade é um sistema em funcionamento diferenciado, no qual o sistema legal é um de seus subsistemas funcionais. O conceito de autopoiesis desenvolvido por Maturana e Varela (1980) é incorporado por Luhmann, ao observar que os subsistemas funcionais da sociedade são sempre auto-referenciais, significando que eles produzem e reproduzem a si próprios. 
Teubner (1989), a partir da análise do Direito à luz da Teoria dos Sistemas, introduz o conceito de Direito Reflexivo, ao procurar estabelecer as condições da comunicação sistema/ambiente, equivalendo à interação do sistema jurídico com os subsistemas social, político e econômico. A visão sociológica do Direito, na perspectiva da Teoria dos Sistemas, é objeto de estudos por vários pesquisadores.

A Psicologia utiliza a perspectiva sistêmica no âmbito mais pragmático do que teórico. É nesta perspectiva que a Teoria Sistêmica penetrou, por exemplo, na área da mediação de conflitos, um novo campo de atuação profissional cada vez mais utilizado na esfera jurídica.

\section{Mediação de conflitos}

A Teoria dos Sistemas trouxe uma contribuição empírica na mediação de conflitos, área de grande ascensão no Brasil a partir da década de 1990 . Hoje temos uma literatura apresentando as correntes, tendências e as experiências nesta área (Cezar-Ferreira, 2004; Fisher \& Ertel, 1997; Haynes \& Marodin, 1996; Highton \& Alvarez 1999; Krüger, 1998; Schnitman, 1999).

O que vem a ser mediação de conflitos? Trata-se de um método pragmático de resolução de conflitos, visto como prática, mas também como área de conhecimento oriunda dessa prática. Atualmente a exigência para formação de mediadores é baseada em conhecimentos teóricos multidisciplinares, provenientes de vários campos do saber, tais como: Direito, Psicologia, Comunicação e Sociologia, denotando uma dimensão inter e transdisciplinar. Tal prática, nascida na área de Direito na Universidade de Harvard, e inicialmente com único objetivo de chegar a um acordo em situações de conflito, com o aperfeiçoamento dos processos de mediação, o objetivo se ampliou, visando ao desenvolvimento da alteridade ou ao reconhecimento do outro como sujeito pensante, desejante e sofredor, assim como o empowerment dos envolvidos e a flexibilização do desejo.

Vejamos, sucintamente, quais são as principais escolas que definem acordos e relação.

A primeira escola é identificada como linear-tradicional, tendo como parâmetro o modelo Harvard, cuja causa do conflito é o desacordo e o fundamental nessa escola é chegar a um acordo.

A segunda escola foi desenvolvida por S. Cobb (1993, 1994). A prática é baseada no modelo circular narrativo, inspirada nos princípios das teorias dos sistemas. Nele, as causas do conflito se retroalimentam, criando efeito circular e o importante é melhorar as relações interpessoais. Os acordos neste modelo são circunstanciais.

A terceira escola trabalha no denominado modelo transformativo, desenvolvido por Bush e Folger (1992). Este modelo também se interessa pelos aspectos relacionais do conflito, pois os desacordos não são importantes, importando apenas a aquisição de habilidades de tratamento de conflitos.

A mediação de conflitos, conforme o entendimento de Muskat (2005, p. 13), "tem como finalidade buscar acordos entre pessoas em litígio por meio da transformação da dinâmica adversarial, comum no tratamento de conflitos, para uma dinâmica cooperativa, improvável neste contexto".
Esse campo interdisciplinar é cada vez mais utilizado na Psicologia, no Direito e nas questões práticas da vida cotidiana. O uso da mediação na Psicologia é uma prática facilitadora para a justiça, no que concerne ao cumprimento das leis. Uma das áreas em que a mediação tem um impacto muito grande é na questão das separações conjugais, da partilha de bens e da guarda dos filhos.

Neste último contexto, uma transformação importante no campo do Direito familiar, diz respeito a novas modalidades de guarda, que passaram a considerar diferentes possibilidades de garantir o contato entre pais e filhos, mesmo quando os pais se separam. Pais nunca deixarão de ser pais e filhos nunca deixarão de ser filhos. No período de idade em que a convivência dos filhos com ambos os pais é determinante para o seu próprio desenvolvimento, tais modalidades vieram subsidiar os debates sobre a importância, a necessidade e as desvantagens de cada uma delas.

Muitas são as áreas de mediação: destacamos a mediação penal, realizada entre a vítima e o acusado do direito, visando a restaurar a justiça e que se realiza nos presídios e, em outros espaços vinculados à Justiça; mediação educativa ou nas escolas, nas instituições de saúde, nas questões de meio ambiente; mediação comunitária, nas organizações e no trabalho; mediação transcultural e política; no ambiente familiar, tanto na perspectiva transgeracional quanto no interior da mesma geração, nos conflitos conjugais, de filiação, da partilha de bens e, sobretudo da guarda dos filhos.

A questão da guarda dos filhos, discutida nos Estados Unidos desde a década de 1980, inspirou as modalidades que chegaram até nós e que são causa de várias discussões sobre as vantagens e desvantagens dos tipos de guarda.

Na guarda legal conjunta, os filhos têm uma residência principal, mas os pais têm responsabilidades conjuntas pela tomada de decisões importantes. A denominada guarda alternada é atribuída alternadamente a um e a outro dos pais, a guarda física e também legal dos filhos, o que implica a criança passar dias da semana ou meses morando com cada um dos pais.

$\mathrm{Na}$ guarda física conjunta ou compartilhada, implica a divisão do tempo passado com a criança entre os dois genitores. Os guardiões legais são ambos os pais e a criança terá moradias diferentes em período de tempo alternados. A guarda física é conjunta, podendo assumir muitas formas e os pais podem negociar ou modificar a divisão de tempo com a criança, segundo suas necessidades.

Outra modalidade se denomina aninhamento ou nidação, na qual os pais se revezam, mudando-se para casa onde vivem as crianças, em períodos alternados. Finalmente, a guarda legal conjunta, compartilhada ou dividida. Nesta modalidade, pai e mãe dividem a responsabilidade legal sobre os filhos ao mesmo tempo e compartilham as responsabilidades pelas decisões importantes relativas ao filho.

Diante deste quadro com inúmeras opções para a guarda dos filhos, em muitas situações, o recurso da mediação familiar passa a ser de suma importância para resolução de conflitos muito comuns, no que concerne à guarda dos filhos no caso de separação conjugal.

Portanto, a contribuição de princípios da Teoria dos Sistemas permitiu, nessa prática, que profissionais trabalhem visando às mudanças de posições radicais que possibilitam 
reparações e negociações de acordos. São trabalhados, nesse contexto, processos de comunicação que, sem uma intervenção, poderiam levar a uma escalada de conflitos que saindo da esfera verbal (xingamentos, ofensas, gritos), se transformam em ofensas físicas (tapas, socos, murros, empurrões, facadas), numa crescente violência, podendo chegar à morte. Watzlawick, Beavin e Jackson (1988) definem esse fenômeno de escalada simétrica em oposição ao tipo de interação complementar. Essa escalada de violência pode ocorrer na própria família, no trabalho, no trânsito, na rua ou em outros contextos da vida cotidiana.

Assim, o trabalho do psicólogo nas últimas décadas abriu espaço importante no campo jurídico, redefinindo, desta forma, o que veio a se denominar Psicologia Jurídica. Vimos surgir um desenvolvimento teórico e metodológico a partir de investigações científicas, procurando compreender a complexidade desta área tão ampla. Durante muito tempo, a Psicologia Jurídica teve seu saber centrado na prática do psicodiagnóstico e na aprendizagem de técnicas psicológicas. Pouco a pouco o trabalho do psicólogo foi sendo solicitado por advogados e juízes para avaliações qualitativas em caso de dúvida acerca da guarda de crianças.

Embora mais tardiamente, a Psicanálise também abriu um diálogo com o Direito como veremos a seguir.

\section{Contribuições da Psicanálise}

A Psicanálise como um campo de produção de conhecimentos, nesta última década, produziu vários estudos, afluindo reflexões acerca das possíveis interações com o Direito (Altoé, 2004; 2007; Groeninga \& Pereira, 2003; Legendre, 1985,1988,1990; Pereira, 2003a, 2003b, 2003c).

Observamos também um aumento de congressos, encontros, seminários, nacionais e internacionais tendo como tema Direito e Psicanálise, assim como as publicações procurando identificar as similitudes e diferenças entre esses dois campos do saber. Na França, destaca-se o professor de Direito Romano e psicanalista Pierre Legendre, com muitas publicações sobre o tema. No Brasil, esse movimento se inicia com a busca da Psicanálise por parte de juristas, para melhor compreensão dos aspectos psicodinâmicos inerentes aos sujeitos cujos casos estão sob sua responsabilidade.

Groeninga e Pereira (2003) estabelecem um paralelismo entre esses dois campos e observam que tanto o advogado quanto o psicanalista têm em comum a escuta do seu cliente e sua demanda. Há para esses pesquisadores, uma preocupação em analisar o sujeito, tanto o denominado sujeito do Direito "que é aquele que age consciente de seus direitos e deveres, e segue leis estabelecidas em um dado ordenamento jurídico", quanto o denominado sujeito da Psicanálise ou "sujeito do desejo, aquele que está também assujeitado às leis do inconsciente".

No Direito, a objetividade é o conceito mais visado. A sexualidade nesse contexto é a genitalizada. Entrementes, a Psicanálise, visando a identificar conteúdos da subjetividade dos sujeitos, expressa que a sexualidade é "da ordem do desejo". Perguntam-se Groeninga e Pereira: pode o Direito legislar sobre o desejo, ou será o desejo que legisla sobre o Direito? Tanto o Direito quanto a Psicanálise procuram compreender o sujeito e suas relações. Um na perspectiva objetiva dos fatos e a outra, mais subjetiva, tanto no nível do consciente como no inconsciente. De qualquer forma, estamos diante de um único sujeito, mesmo se ele engloba duas realidades distintas.

Esses estudos procuram encontrar as relações entre o que define como o sujeito do desejo para a Psicanálise como seu objeto de estudo e o sujeito do Direito em seus aspectos sociojurídicos no que concerne aos direitos e deveres; o domínio da lei e do exercício social da responsabilidade (Groeninga \& Pereira, 2003).

Quinet (2003) analisa a lei na perspectiva psicanalítica e na óptica do Direito. Para ele há a "Lei simbólica, que rege os homens na condição de seres que habitam a linguagem, e as leis que os homens fazem para regular as relações entre si" (p. 57). Ele considera a Lei simbólica como estrutural, que não depende do lugar, do momento histórico ou da constituição social e que se expressa na cultura mediante as leis, a Constituição, os estatutos e regimentos institucionais, com o objetivo de enquadrar e limitar o gozo de um em relação aos demais.

A Lei simbólica, para a Psicanálise, é expressa no inconsciente por meio de suas formações - sonho, sintoma, chistes - e equivale ao que Freud nomeou como a lei de interdição do incesto. Essa lei é representada pelo pai que não é necessariamente o genitor, mas o pai simbólico que foi mais tarde denominado por Lacan de Nome do Pai, como instância legal, um puro significante.

Guyomard (2007), ao analisar a procriação, observa também que existem as "leis escritas e as leis não escritas". Compreende-se como sendo as escritas, as leis que fazem parte da legislação de cada lugar, e que proíbem o sujeito de cometer alguns atos. Já as leis não escritas são aquelas em que o sujeito por si só e sem que haja a interseção das leis escritas, as obedece, as respeita. A Psicanálise trabalha com a lei no sentido de existir a lei do pai, a lei que proíbe o incesto e o parricídio. Trabalha com o valor da Lei e das leis, com a lei escrita e as não escritas, percebendo assim as diferenças entre a lei, as normas e a ética.

Não resta dúvida que a polissemia da palavra Lei percorre as inúmeras áreas da ciência, desde lei como instituidora da ordem jurídica, da regra escrita, as leis da natureza, leis físicas, biológicas, lei da gravidade, leis canônicas a leis sociais, econômicas até lei para a psicanálise. Para Freud, lei básica, lei fundamental ou lei primeira, e, para Lacan, a lei do pai/nome do pai. Na Psicanálise, a lei fundante é aquela que estrutura o sujeito a partir da proibição do incesto e as conseqüências disso são a estruturação da sociedade e o ordenamento jurídico. Esta tentativa de integração dos dois campos do conhecimento tem sido tema de debate em várias reuniões científicas, realizadas até hoje.

As transformações oriundas do avanço tecnológico concorrem para o questionamento e a revisão de alguns conceitos, como o que vem a ser um pai e o que vem a ser uma mãe, tendo em vista que, dimensões biológica, sociológica e psicológica se cruzam. Pai e genitor têm funções diferentes, mas que podem estar juntas numa mesma pessoa, como podem estar totalmente dissociadas. Em tempos de barriga de aluguel, inseminação artificial, doador de esperma, fecundação in vitro, e outras variações, o pai psicossocial pode não ser o pai genitor, o mesmo podendo se aplicar à maternidade. Nesse contexto de grandes transformações da 
tecnociência e das repercussões que ela provoca na estrutura e na dinâmica familiar, é extremamente importante o diálogo entre os vários campos do saber.

Essas são algumas das questões em debate pelas diversas áreas aqui abordadas, que procuram, mediadas pelo diálogo, portanto pela possibilidade clínica, encontrar opções para o aprimoramento do laço social como dimensão humana.

\section{Considerações Finais}

Procuramos, neste ensaio, indicar algumas transformações ocorridas nas relações entre o Direito, a Psicologia e a Metapsicologia, a partir de determinadas idéias lançadas no artigo publicado em 1983.

Consideramos que do ponto de vista do conhecimento da população, em relação às leis e sua aplicação, ainda existem muitas lacunas e distorções. Observamos a tendência à interdisciplinaridade, como uma forma de encontrar caminhos para enfrentar a crise que se instalou na sociedade em relação aos valores, a quebra de paradigmas tradicionais, sem que outro tenha surgido para dar conta da realidade em plena transformação, como uma das conseqüências do rápido desenvolvimento tecnológico.

Convém salientar que a Psicologia Jurídica está conquistando um espaço importante na área do Direito. Destacamos os trabalhos desenvolvidos em Santa Catarina, São Paulo, Rio de Janeiro, Brasília e outros estados e nos mais variados âmbitos do Judiciário. No Ceará, a Universidade de Fortaleza/UNIFOR desenvolve um Escritório de Prática Jurídica (EPJ) que, por intermédio de uma equipe multidisciplinar, não é só formadora de profissionais, como também propicia um atendimento integrado à comunidade carente que utiliza esse serviço. Trata-se aqui do nível da pragmática.

No nível teórico, por nos encontrarmos no alvorecer de uma tentativa de um diálogo epistemológico entre as mais variadas disciplinas, podemos correr o risco de gerar uma grande confusão conceitual juntando-se referências teóricas de contextos heterogêneos. Portanto, é necessário estar atento à necessidade de clareza teórica, que poderá ser precisada a partir do intenso trabalho de pesquisa e revisão constante de conceitos, como o que aqui pretendemos apresentar.

Experiências como essas estão em lento crescimento no Brasil, mas que acenam para maior engajamento e um diálogo mais profícuo entre as disciplinas na busca de maior compreensão da realidade humana.

\section{Referências}

Altoé, S. (Org). (2004). Sujeito do Direito, sujeito do Desejo Direito e Psicanálise. Rio de Janeiro: Revinter.

Altoé, S. (Org.) (2007). A lei e as leis - Direito e Psicanálise. Rio de Janeiro: Revinter.

Andreotti Neto, N. (Org.) (1991). Código Penal. São Paulo: Rideel.

Angher, A. J. (Org.) (2003). Novo Código Civil: Lei Nº 10.406/2002 ( $1^{a}$ ed.). São Paulo: Rideel.

Barros, F. S. B. (2001). O interesse superior da criança como paradigma da filiação socioafetiva. Em M. C. C. Brauner (Org), O Direito da Família: descobrindo novos caminhos (pp.213248). São Leopoldo: Edição da Autora.
Bucher, J. S. N. F. (1979a). Aspectos Psicológicos da separação conjugal. Psicologia Atual, 9, 10-13.

Bucher, J. S. N. F. (1979b). Desquite, Divórcio e concubinato. Arquivos do Ministério da Justiça, 177-182.

Bucher, J. S. N. F. (1981a). Ausência do Pai: uma introdução ao tema. Revista de Psicologia, 1, 107-122.

Bucher, J. S. N. F. (1981b). Familien Therapie in Brasilien: Arbeit mit Familien und Judengerichten. Kontext, Universität Giessen, 4(1), 5-14.

Bucher, J. S. N. F. (1999). O casal sob novas formas de interação. Em T. F. Carneiro (Org.), O casal e a família em transformação (pp.62-95). Rio de Janeiro: Nau.

Bucher-Maluschke, J. S. N. F. (2003). Relações Conjugais em transformação e sofrimento psíquico numa sociedade em transição. Em I. Costa, A. Holanda, F. Martins \& M. I. Tafuri (Orgs.), Ética, Linguagem e Sofrimento (pp.295-307). Brasília: Positiva/ABRAFIPP.

Bucher-Maluschke, J. S. N. F. \& Costa I. I. (2003). Family Therapy in Brazil: Memory and Development. Em Kit S. Ng (Org.), Global Perspectives in Family Therapy: Development, Practice, Trends (pp.295-206). New York/Sussex: Brunner-Routledge.

Bush, R. A. B. \& Folger, J. P. (1992). The Dilemmes of Mediation Practice: A Study of Ethical. Washington: NIDR.

Cezar-Ferreira, V. A. M. (2004). Família, separação e mediação: uma visão sócio jurídica. São Paulo: Editora Método.

Cobb, S. (1993). Empowerment and Mediation. Negotiation Journal, 3, 245-260.

Cobb, S. (1994). Theories of responsability. The Social Construction of Intentions of Mediation. Discurse Processes, 18(2), 165-186.

Constituição da República Federativa do Brasil (1988). Brasília: Horizonte Editora.

Costa, D. D. (2001). Reconhecimento jurídico e situação fática das famílias mono parentais no Brasil. Em M. C. C. Brauner (Org.), O Direito da Família: descobrindo novos caminhos (pp. 92-161). São Leopoldo: Edição da Autora.

Cruz, R. M., Maciel, S. K. \& Ramirez, D. C. (Orgs.) (2005). $O$ trabalho do psicólogo no campo jurídico. São Paulo: Casa do Psicólogo.

Fisher, R. \& Ertel, D. (1997). Estratégias de negociação. Rio de Janeiro: Ediouro.

Freud, S. (1972). Totem e Tabu e outros trabalhos. Obras Completas de Sigmund Freud. Vol. XIII (1913-1914). Rio de Janeiro: Imago Editora.

Groeninga, G. C. \& Pereira R. C. (Org.) (2003). Direito de Família e Psicanálise. Rumo a uma nova epistemologia. Rio de Janeiro: Imago.

Guyomard, P. (2007). A Lei e as leis. Em S. Altoé (Org.), Direito e Psicanálise (pp. 1-59). Rio de Janeiro: Revinter.

Haynes, J. M. \& Marodin, M. (1996). Fundamentos na mediação familiar. Porto Alegre: Artes Médicas.

Highton, E. I. \& Alvarez, G. S. (1999). A mediação no cenário jurídico: seus limites. Em D. F. Schnitman, \& S. Littlejohn (Orgs.), Novos Paradigmas em mediação Porto Alegre: Artmed.

Jovchelovitch, S. (2000). Representações sociais e esfera pública: a construção simbólica dos espaços públicos no Brasil. Petrópolis. Vozes.

Krüger, L. L. (1998). Mediação Familiar: articulando diferenças, construindo alternativas. Nova realidade do Direito de Família. Tomo I. Rio de Janeiro: COAD. 
Legendre, P. (1985). Leçons IV - L'inestimable objet de la transmission. Étude sur le principe généalogique em occident. Paris: Fayard.

Legendre, P. (1988). Leçons IV, suíte. Le dossier occidental de la parenté. Textes juridiques indésirables sur la généalogie. Paris: Fayard.

Legendre, P. (1990). Leçons IV, suíte 2, Filiation. Fondement généalogique de la psychanalyse. Paris: Fayard.

Levi-Strauss, C. (1982). Estruturas Elementares do Parentesco. Petrópolis: Vozes.

Luhmann, N. (1983). Sociologia do Direito, Vol. I. Rio de Janeiro: Edições Tempo Brasileiro.

Luhmann, N. (1988). The unit of legal sistem. Em G. Teubner (Org.), Autopoietic Law: a new approach to law and society. Berlim/Nova York: Walter de Gruyter.

Luhmann, N. (1995). Social Systems. Stanford/Califórnia: Stanford University Press.

Maturana, H. \& Varela, F. J. (1980). Autopoiesis and cognition. Boston: Reidel.

Menin, M. S. S. (2000). Representações sociais de justiça em adolescentes infratores: discutindo novas possibilidades de pesquisa, Psicologia: Reflexão e Crítica, 13(1), 59-71.

Ministério da Justiça (1990). Estatuto da Criança e do Adolescente (Lei no. 8.069/1990). Brasília.

Muskat, M. E. (2005). Guia Prático de mediação em conflitos em famílias e organizações. São Paulo: Summus Editorial.

Pereira, R. C. (2003a). A primeira lei é uma lei d Direito de Família: A lei do Pai e o fundamento da lei. Em G. C. Groeninga \& R. C. Pereira (Orgs.), Direito de Família e Psicanálise: Rumo a uma nova epistemologia (pp.17-29). Rio de Janeiro: Imago.

Pereira, R. C. (2003b). A criança não existe. Em G. C. Groeninga \& R. C. Pereira (Orgs.), Direito de Família e Psicanálise: Rumo a uma nova epistemologia (pp.205-206). Rio de Janeiro: Imago.
Pereira, R. C. (2003c). Direitos Humanos, Psicanálise e Inclusão Social. G. C. Groeninga \& R. C. Pereira (Orgs.), Direito de Família e Psicanálise: Rumo a uma nova epistemologia (pp.155161). Rio de Janeiro: Imago.

Quinet, A. (2003). O gozo, a 1;ei e as versões do pai.Em: G.C. Groeninga e R.C. Pereira, (Coord.), Direito da Família e Psicanálise: rumo a uma Nova Epistemologia (pp. 55-65). Rio de Janeiro: Imago.

Rigonatti, S. P. (Org.) (2003). Temas de Psiquiatria Forense e Psicologia Jurídica. São Paulo: Vetor Editora PsicoPegagógica.

Schnitman, D. F. (1999). Novos paradigmas na resolução de conflitos. Em D. F. Schnitman, \& S. Littlejohn (Orgs.), Novos paradigmas em mediação. Porto Alegre: Artmed.

Shimizu, A. M. \& Menin, M. S. S. (2004). Representações Sociais de lei, justiça e injustiça: uma pesquisa com jovens argentinos e brasileiros utilizando a técnica de evocação livre de palavras. Estudos de Psicologia, 9(2): 239-247.

Silva, D. M. P. (2003). Psicologia Jurídica no processo civil brasileiro. São Paulo: Casa do Psicólogo.

Souza, M. (1999). A Experiência da lei e a lei da experiência: ensaios sobre práticas sociais e subjetividade no Brasil. Rio de Janeiro: Revan.

Teubner, G. (Org.) (1988). Autopoietic law: a new approach to law and society. Berlim/Nova York: Walter de Gruyter.

Teubner, G. (1989). O direito como sistema autopoietico. Lisboa: Fundação Calouste Gulbenkian.

Teubner, G. (1996). Droit et reflexivité: l'auto-référence em droit et dans l'organization. Belgique: Bruyland.

Watzlavick, P., Beavin, J. H. \& Jackson, D. D. (1988). Pragmática da Comunicação Humana. São Paulo: Cultrix. 